\title{
Muscovy Duck Parvovirus Infection with Epicarditis in Bali, Indonesia
}

Gusti Ngurah Mahardika ${ }^{1 *}$, Made Bagus Arya Permana Ardiana Putra ${ }^{1}$, Ni Putu Sutrisna Dewi ${ }^{1}$, Ni Made Ritha Krisna Dewi ${ }^{1}$ and Ida Bagus Oka Winaya ${ }^{2}$

${ }^{1}$ The Animal Biomedical and Molecular Biology Laboratory, Faculty of Veterinary Medicine, Udayana University, Denpasar 80226, Bali, Indonesia

${ }^{2}$ Pathology Laboratory, Faculty of Veterinary Medicine, Udayana University, Denpasar 80226, Bali, Indonesia

*Corresponding author: Gusti Ngurah Mahardika, The Animal Biomedical and Molecular Biology Laboratory, Faculty of Veterinary Medicine, Udayana University, Denpasar, Bali, Indonesia, Tel: +623618423062; Fax: +62361223791; E-mail: gnmahardika@indosat.net.id

Rec date: Feb 28, 2016; Acc date: Apr 04, 2016; Pub date: Apr 06, 2016

Copyright: (c) 2016 Mahardika GN, et al. This is an open-access article distributed under the terms of the Creative Commons Attribution License, which permits unrestricted use, distribution, and reproduction in any medium, provided the original author and source are credited.

\begin{abstract}
Muscovy duck parvovirus (MDPV) is threatening industry and backyard Muscovy duck poultry throughout the world. Here, we confirmed its presence in Indonesia for the first time. The outbreak described in this study occurred in a small fatty liver (French: foie gras) industry in Tabanan, Bali, and affected ducklings aged 2-3 weeks. Although older Muscovy ducks were present at the facility, they did not present signs of illness. Among the ducklings, the morbidity and mortality rates were $100 \%$ and $90 \%$, respectively. The initial incidence began on 15 June 2014 and ended a month later. It reoccurred in January 2015. Clinical signs were lethargy, anorexia, watery diarrhoea, and dyspnea. The most frequent pathological lesions were cardiac enlargement with pale pericardia, haemorrhage, and enlargement of the liver. Dominant histopathology features were severe enteritis, epicarditis, and hepatitis. Using polymerase chain reaction (PCR) and published primer pairs NS1/REP and VP1, MDPV infection was confirmed with whole DNA isolated from the heart and liver homogenates. Sequencing of the PCR products resulted in $900 \mathrm{bp}$ NS1/REP and 1200 bp VP1 fragments specific to MDPV. The virus sequences from the two separated incidences were completely homologous with one another. Now that MDPV has been detected in Indonesia, it should be included in the differential diagnosis when evaluating ducklings with MDPV-associated symptoms.
\end{abstract}

Keywords: Muscovy duck; Parvovirus; Case; Epicarditis; Hepatitis; cDNA sequence; NS1/REP; VP1

\section{Introduction}

Muscovy duck parvovirus (MDPV) has been discovered in Europe, the United States, Japan, China, and Taiwan [1-6]. The virus is threatening Muscovy duck meat and egg production in various countries. The leading affected country in Europe is France, where Muscovy and Mule ducks are also used for fatty liver (foie gras) production by forced feeding [7]. In Asia, major foie gras exporters are China and Thailand. In most countries, this waterfowl is kept as a backyard-scavenging system, but it is also becoming a valuable food commodity [8-10] as it is the case in Indonesia. Muscovy duck meat is the key ingredient of a favourite local food in Bali, so called lawar kuir'. Additionally, Bali, being one of the major world tourism destinations, also has some businesses that produce foie gras to supply the French delicacy for foreign travellers to the island.

The MDPV is classified in the genus Dependovirus. This group is also known as the adeno-associated viruses, which are replication defective by nature and require the presence of a helper virus, typically an adenovirus, to successfully replicate [11]. Establishing a definitive diagnosis of MDPV is complicated. Genetically, the virus is closely related to goose parvovirus (GPV), which infects goslings [12-14], and previous work has demonstrated antigenic cross-reaction between these two viruses [15]. Clinical and post-mortem findings in MDPVinfected ducklings resemble those of GPV-infected goslings [11], and GPV can cause high mortality in Muscovy ducks as well $[16,17]$. Further complicating diagnosis of MDPV, the clinical symptoms of MDPV infection are similar to those of not only GPV infection, but also of duck enteritis and duck hepatitis type I infections [18].
Here, we describe the clinical signs, post-mortem pathologic lesions, and confirmation of MDPV in Indonesia using sequencing of polymerase chain reaction (PCR) products.

\section{Materials and Methods}

Sample collection: On 14 July 2014 and in January 2015, the owner of a newly founded foie gras industry in the Tabanan district of Bali reported a high mortality of Muscovy ducklings, while the older Muscovy ducks were not affected. The company generally purchased 2week-old ducklings from locals with backyard birds.

Field observation, necropsy, and sample collection were carried out twice; once in July 2014 (incidence 1) and once in January 2015 (incidence 2). Three ducklings were necropsied from each visit. All clinical, epidemiological, and pathological findings were recorded.

Virus isolation and identification: Virus isolation was conducted in specific antibody-free chicken eggs to test for possible Newcastle Disease virus (NDV) infection and in backyard Muscovy duck eggs to test for MDPV. The presence of NDV was confirmed using a standard haemagglutination inhibition (HI) assay [19], and reversetranscriptase (RT)-PCR applying a published primer pair [20]. The Avian Influenza $\mathrm{H} 5 \mathrm{~N} 1$ detection was conducted as previously published [21]. The presence of MDPV was confirmed using PCR with primer pairs covering the NS1 [12] or REP [6], hereinafter is mentioned as NS1-REP, and VP1 genes as previously described [1] and then sequencing the results at the Eijkman Institute Jakarta using BigDye $^{\infty}$ Terminator v3.1 Cycle Sequencing Kit (Life Technologies) following the accompanying manual. The total DNA was isolated and purified from heart and liver tissue homogenates, as well as from the allantois fluid of inoculated Muscovy duck eggs, using a DNA isolation kit (Invitrogen) following the protocol in the provided manual. The 
sequences were edited and aligned using ClustalW and subjected to BLAST using the Mega5 software [22]. Upon confirmation, a phylogenetic analysis of both gene fragments was conducted together with the available GenBank MDPV and GPV sequences from various countries.

Tissue sample preparation: Tissue samples showing pathological lesions were preserved in buffered formaldehyde and embedded in a paraffin block. The tissues were cut into sections $2-3 \mu \mathrm{M}$ thick and stained with haematoxylin-eosin (HE).

Accession numbers: All sequences discovered in this study have been submitted to GenBank with the following accession numbers KR004178-KR004181.

\section{Results}

In incidence 1, the total number of Muscovy ducks on the premises was 230 , which included 30 adults, 50 sub-adults (aged 2-3 months), and 150 ducklings (2-3 weeks old). The facility was located in a highland rice field, which was separated from other birds in the community. Upon our visit, the outbreak had affected all of the ducklings, whereas the ducks in the older age groups were completely healthy. The daily number of deaths was generally three to six. Death usually occurred 2-3 days after the appearance of clinical signs. Only eight out of 150 ducklings survived, all showing retracted growth. In incidence 2, 24 ducklings were affected; of those, 13 were sick and nine died.

Clinical signs were lethargy, anorexia, watery diarrhoea, dyspnea, and torticollis. Consistent pathological findings were heart dilatation with pale wall, especially around the atrium, and fibrinous pericardium (Figure 1). The liver was consistently enlarged with multi-focal necrosis. Severe lung necrosis, tracheal congestion, and intestinal haemorrhage were observed in two birds, one from each incidence. Consistent microscopic lesions were severe enteritis necroticans from serous to mucous membrane, especially in and around the crypts of Lieberkuhn (Figure 2), diffuse hepatitis (Figure 3), and epicarditis (Figure 4). Other macroscopic and microscopic findings, which were inconsistent among the necropsied birds, were haemorrhage in spleen, pancreas, and kidney, as well as severe inflammation with complete follicle atrophy in the spleen, necrosis of the bursa of Fabricius, multifocal necroses in the pancreas, interstitial myocarditis, and perivascular cuffing in the brain.

DNA was isolated from both heart and liver tissue homogenates collected in both cases and from viruses harvested from Muscovy duck eggs. Specific bands were visualized upon PCR of both NS1/REP and VP1 gene fragments in the DNA from the ducklings, but not from the harvested Muscovy duck eggs. NDV could be confirmed from one of the samples that showed torticollis and severe lung haemorrhage (Figure 2). The result of AIV detection was negative. The MDPV-PCR product sequences of both gene fragments were each $100 \%$ homologous between incidents. The BLAST results showed that the NS1/REP and the VP1 have $99 \%$ homology with the MDPV sequences available in GenBank, and that the sequence coverage was $100 \%$. The readable sequences of NS1/REP and VP1 were 911 and 1,069 bp, respectively.

Phylogenetic analysis of the NS1/REP gene fragment (Figure 5) shows that the MDPV detected in this study, designated as UDAYANA-MDPV-A and UDAYANA-MDPV-B, form a common cluster with all MDPV, including Barbarie DPV strain FM/Hungary available in GenBank, but distinctly separate from GPV. In the VP1 sequence phylogeny reconstruction (Figure 6), the result shows the same pattern, except that the MDPV-GX5 strains were significantly separated from the others (bootstrap value 99). Deduced amino-acid residue analyses (not shown) show that the UDAYANA-MDPVs have unique amino acid residues, isoleucine (I) at position no. 496 of NS1/REP and arginine (R) as amino acid no. 160 of VP1, while other published strains have threonine $(\mathrm{T})$ and lysine $(\mathrm{K})$, respectively. The amino acid numbering is based on the published sequence of MDPVGX5, acc. number KM093740.
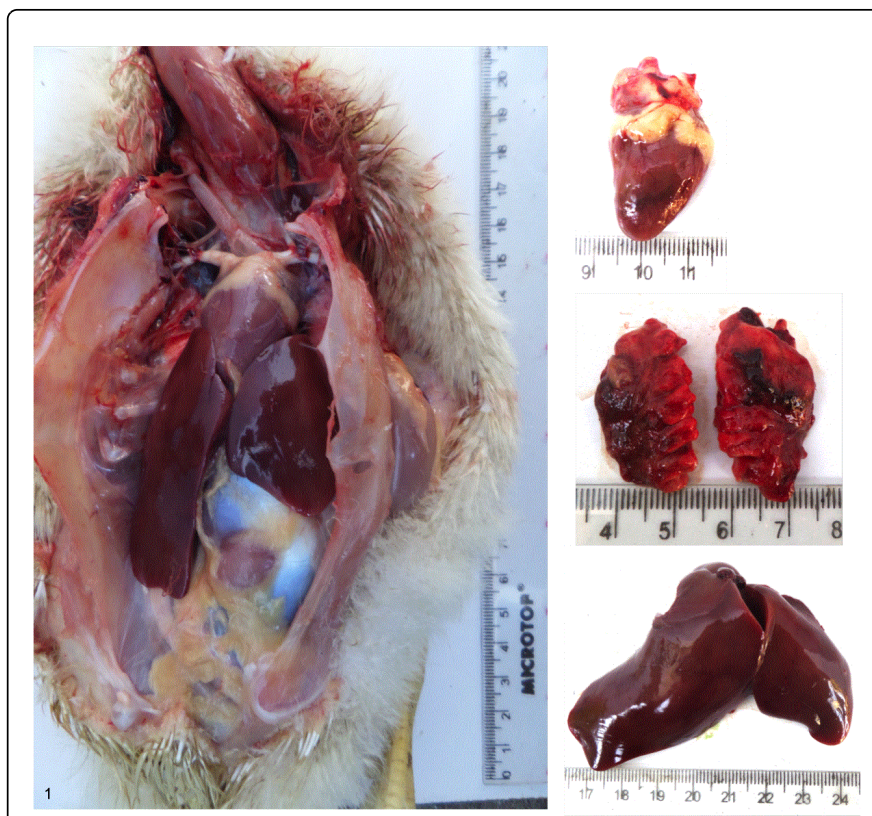

Figure 1: Representative MDPV incidence in Bali, Indonesia showing an in situ necropsied animal (left), and its heart (upper right), lungs (middle right), and liver (bottom right).

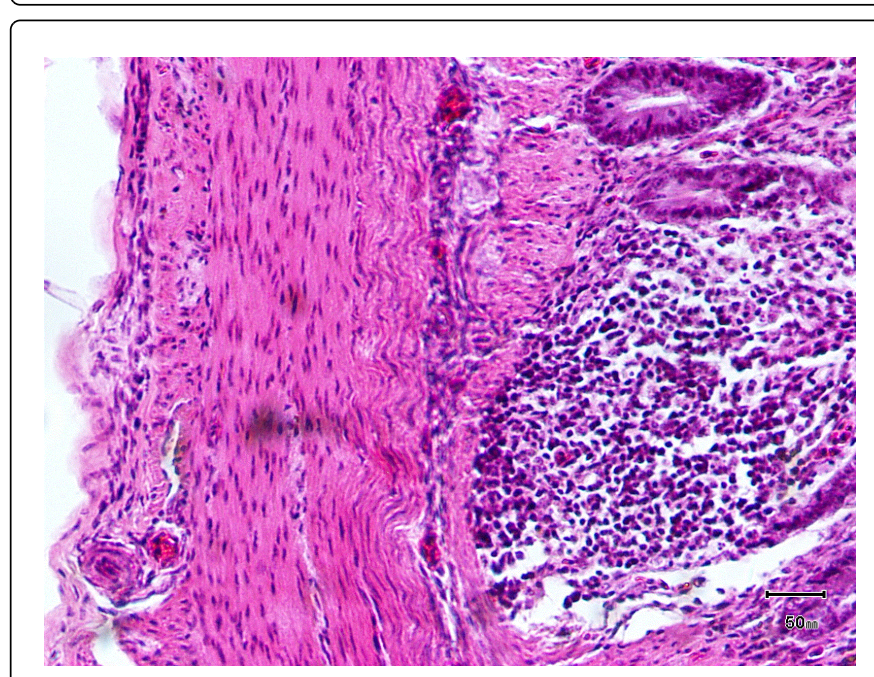

Figure 2: Histology of an intestine from a representative MDPV incidence in Bali, Indonesia. The tissue sections were stained with $\mathrm{HE}$ and observed under a microscope (magnification $20 \times 10$ ). 


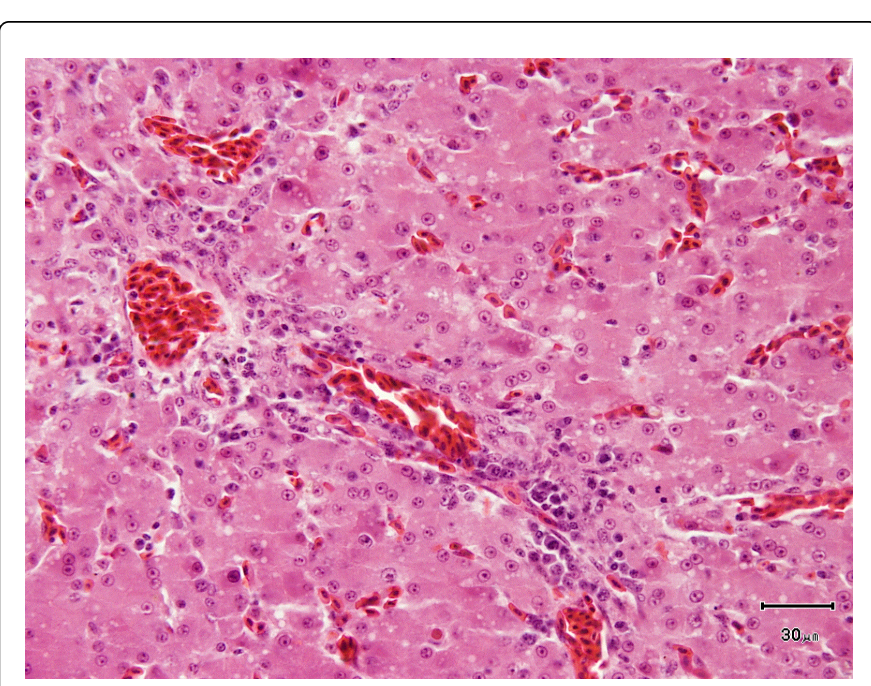

Figure 3: Histology of an liver from a representative MDPV incidence in Bali, Indonesia. The tissue sections were stained with $\mathrm{HE}$ and observed under a microscope (magnification $40 \mathrm{x} 10$ ).

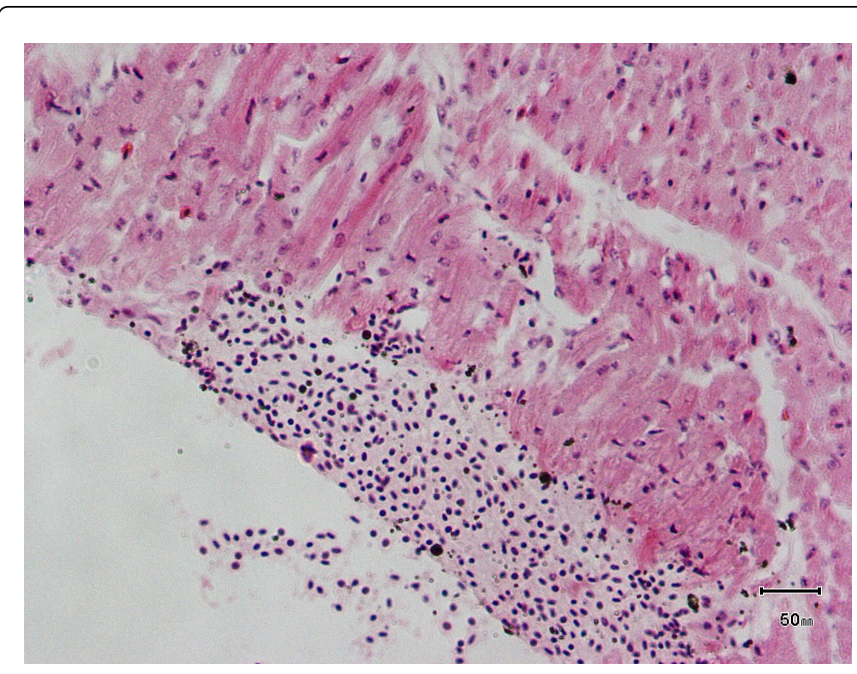

Figure 4: Histology of an myocardium from a representative MDPV incidence in Bali, Indonesia. The tissue sections were stained with $\mathrm{HE}$ and observed under a microscope (magnification $20 \times 10$ ).

\section{Discussion}

This is the first report of MDPV in Indonesia. The disease was not listed in the initial differential diagnosis, as there has been no previous report on its possible presence in the area. Having clinical signs of torticollis and extremely high mortality, the tentative diagnosis was NDV or avian influenza virus (AIV) infection. NDV is known to infect various bird species. The NDV of duck origin is pathogenic to chicken, duck, and Muscovy duck $[23,24]$. The high mortality initially led to a suspicion of AIV of H5N1 subtype. Both NDV and AIV are endemic throughout Indonesia, including in Bali [25-31]. NDV, but not AIV, was successfully confirmed using egg culture, serology, and RT-PCR (not shown). Additionally, no bacteria could be detected from lung, myocardium and liver tissues following culture in nutrient and blood agar media. Escherichia coli were cultivable from intestine tissue and assumed to be normal intestinal microflora.

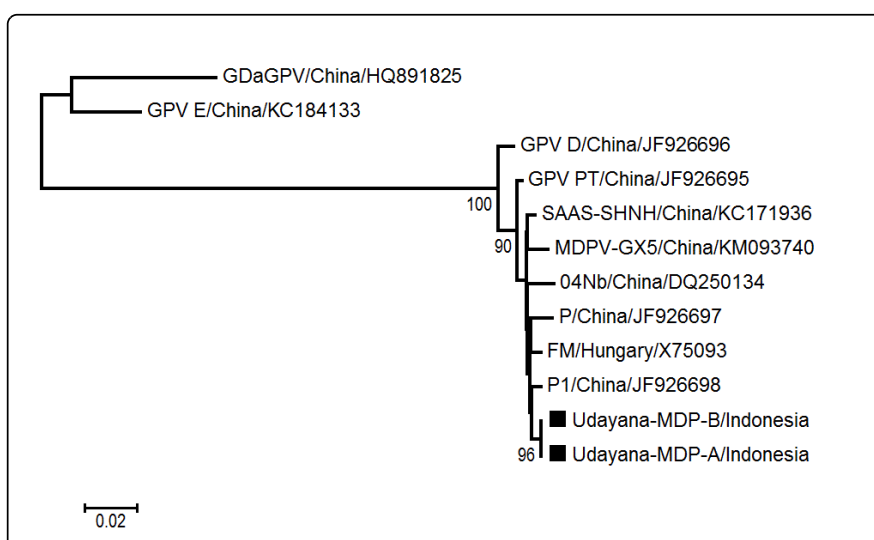

Figure 5: Phylogenetic analysis of MDPV NS1/REP of UDAYANAMDPA and MDPB together with the available GenBank sequence data of MDPV and GPV strains from various countries. The strain name, country origin, and accession number of each strain are indicated. The trees were constructed using the neighbour-joining method with K-2 parameters and bootstrap with 1,000 replicates. Bootstrap values of higher than 90 are shown. The analysis was done using a Mega5 package [22].

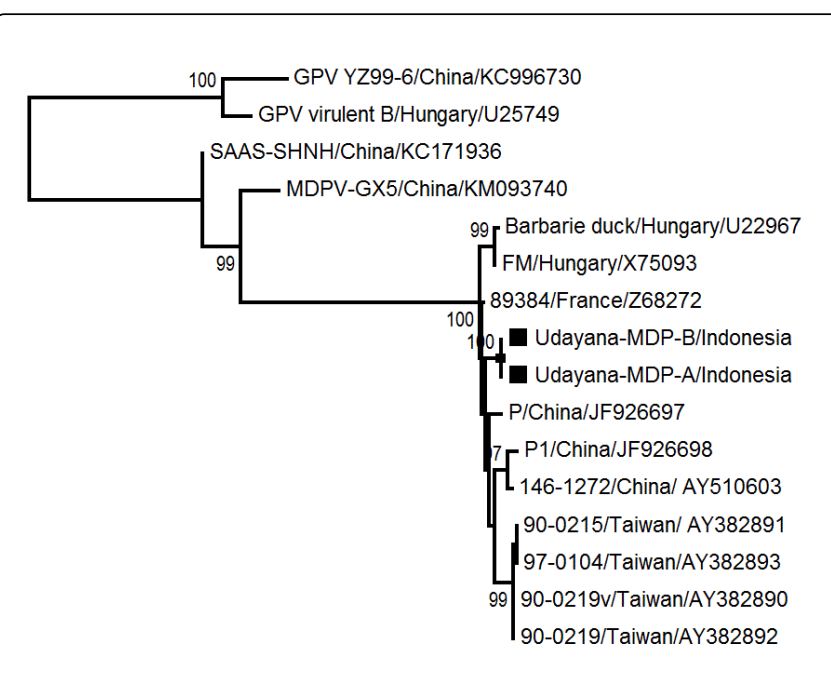

$\longmapsto 0.02$

Figure 6: Phylogenetic analysis of MDPV NS1/REP and VP1 of UDAYANA-MDPA and MDPB together with the available GenBank sequence data of MDPV and GPV strains from various countries. The strain name, country origin, and accession number of each strain are indicated. The trees were constructed using the neighbour-joining method with K-2 parameters and bootstrap with 1,000 replicates. Bootstrap values of higher than 90 are shown. The analysis was done using a Mega5 package [22].

The histopathological picture of the myocardium did not fit with any NDV reports, so we continued to look for another explanation. The consistent epicarditis and diffuse hepatitis led to the possibility of MDPV or other diseases, such as duck viral hepatitis virus $[32,33]$. The 
Page 4 of 5

applied PCR protocol testing for MDPV detected sharp signals from the heart and tissue homogenates, but not from the eggs. Sequencing confirmed that the products were NS1/REP and VP1 specific to MDPV. The failure to grow the virus in Muscovy duck eggs might have been caused by the presence of maternal antibodies in the eggs. It is almost impossible to find an MDPV antibody-free egg, as the appropriate detection test is not available. However, it should be possible to cultivate MDPV in MDPV antibody-free Muscovy duck eggs [1].

Almost all clinical and pathological signs resembled those previously published for typical MDPV infection [16]. Consistent clinical signs were lethargy, anorexia, watery diarrhoea, and dyspnea. Consistent pathological findings were heart dilatation with pale wall, especially around the atrium, and rounded tips, as well as hepatomegaly with multi-focal necrosis. Consistent microscopic lesions were enteritis, epicarditis, and diffuse hepatitis. The novel macroscopic lesion of epicarditis has not been described in all animal parvovirus infections.

The sequences of the PCR products of both gene fragments were each $100 \%$ homologous between collection times. This is typical for parvovirus population sequence data $[34,35]$. The MDPV identified in this study, UDAYANA-MDPA and -MDPB, are typical MDPV in that they share a common cluster with all worldwide MDPV strains and are distinctly separated from GPV. In contrast, one unusual MDPV, SAASSHNA strain, is believed to be the result of recombination between MDPV and GPV [36]. The phylogeny of NS1/REP also indicates that some GPV's are clustered with MDPV. This might explained the former observation that GPV can infect Muscovy duck [16,17]. Two unique substitutions are found in the UDAYANA-MDPV, which are T496I in NS1/REP and K169R in VP1 (MDPV-GX5 numbering). These unique residues can be used as molecular markers of the UDAYANA-MDPV strains. The possible role of these substitutions on the biology of these MDPV strains needs to be elucidated, and they may explain the novel epicarditis caused by these strains.

The spread and the history of MDPV in Indonesia need to be investigated. We believe that MDPV is not new in Indonesia. As reported in Taiwan, GPV and MDPV seem to be endemic there [6]. The agent seems to circulate since long time in Bali, as there was no history of animal transport from other island in Indonesia prior to the incidence of the case under studied. The owner of the farm has collected adult duck from his neighbours. The obvious outbreak might have happened due to the presence of high density of susceptible species. This might have caused the presence of anti-MDPV antibody in eggs that lead to the failure to isolate the virus as described above.

The economic loss due to MDPV might negatively affect Muscovy duck production. Now that this virus has been detected in Indonesia, it should be considered as a possibility when evaluating sick ducklings. This outbreak occurred following the transport of very young ducklings, and it is possible that transport stress and age are predisposing factors. To avoid predisposing young ducklings to MDPV infection, transport should be avoided or occur at six weeks of age or older. Moreover, vaccination against MDPV should be applied if large production facilities are to be established. Vaccines that are based on inactivated or attenuated GPV or MDPV strains have been applied in Europe [37-39]. Until a local vaccine can be developed, these vaccines should be imported into Indonesia from Europe.

\section{Acknowledgements}

The case was part of the diagnostic laboratory assistantship at the Faculty of Veterinary Medicine, Udayana University. The Animal Biomedical and Molecular Biology Laboratory, Udayana University provided the funding for the PCR and sequencing experiments as well as for the publication costs.

\section{Funding Information}

The Animal Biomedical and Molecular Biology Laboratory, Faculty of Veterinary Medicine Udayana University, Denpasar, Bali, Indonesia.

\section{References}

1. Poonia B, Dunn PA, Lu H, Jarosinski KW, Schat KA (2006) Isolation and molecular characterization of a new Muscovy duck parvovirus from Muscovy ducks in the USA. Avian Pathol 35: 435-441.

2. Lu YS, Lin DF, Lee YL, Liao YK, Tsai HJ (1993) Infectious bill atrophy syndrome caused by parvovirus in a co-outbreak with duck viral hepatitis in ducklings in Taiwan. Avian Dis 37: 591-596.

3. Woolcock PR, Jestin V, Shivaprasad HL, Zwingelstein F, Arnauld C, et al. (2000) Evidence of Muscovy duck parvovirus in Muscovy ducklings in California. Vet Rec 146: 68-72.

4. Zhao H, Xie Z, Xie L, Deng X, Xie Z, et al. (2014) Molecular characterization of the full muscovy duck parvovirus, isolated in guangxi, china. Genome Announc 2.

5. Le Gall-Reculé G, Jestin V (1994) Biochemical and genomic characterization of muscovy duck parvovirus. Arch Virol 139: 121-131.

6. Chang PC, Shien JH, Wang MS, Shieh HK (2000) Phylogenetic analysis of parvoviruses isolated in Taiwan from ducks and geese. Avian Pathol 29: 45-49.

7. Pingel H (2011) Waterfowl Production for Food Security. In: Lohhmann Information, Wing 46: 32-42.

8. Yakubu A (2013) Characterisation of the local Muscovy duck in Nigeria and its potential for egg and meat production. World's Poultry Science Journal 69: 931-938.

9. Bleich EG, Rhissa Z, Mack S (2005) The FAO special programme for food security: livestock diversification - a case study in Chad. World's Poultry Science Journal 61: 23-29.

10. Banga-Mboko H, Maes D, Leroy PL (2007) Indigenous Muscovy ducks in Congo-Brazzaville. 1. A survey of indigenous Muscovy duck management in households in Dolisie City. Trop Anim Health Prod 39: 115-122.

11. MacLachlan NJ, Dubovi EJ (2011) Fenner's Veterinary Virology. (4th Edn) London, Academic Press.

12. Zadori Z, Stefancsik R, Rauch T, Kisary J (1995) Analysis of the complete nucleotide sequences of goose and muscovy duck parvoviruses indicates common ancestral origin with adeno-associated virus 2. Virology 212: 562-573.

13. Zadori Z, Erdei J, Nagy J, Kisary J (1994) Characteristics of the genome of goose parvovirus. Avian Pathol 23: 359-364.

14. Tsai HJ, Tseng CH, Chang PC, Mei K, Wang SC (2004) Genetic variation of viral protein 1 genes of field strains of waterfowl parvoviruses and their attenuated derivatives. Avian Diseases 48: 512-521.

15. Li M, Yu TF (2013) Immunologic cross-reactivity between Muscovy duck parvovirus and goose parvovirus on the basis of epitope prediction. Brazilian Journal of Microbiology 44: 519-521.

16. Glavits R, Zolnai A, Szabo E, Ivanics E, Zarka P, et al. (2005) Comparative pathological studies on domestic geese (Anser anser domestica) and Muscovy ducks (Cairina moschata) experimentally infected with parvovirus strains of goose and Muscovy duck origin. Acta Veterinaria Hungarica 53: 73-89.

17. Wang S, Cheng XX, Chen SY, Zhu XL, Chen SL, et al. (2013) Genetic characterization of a potentially novel goose parvovirus circulating in 
Citation: Mahardika GN, Putra MBAPR, Dewi NPS, Dewi NMRK, Winaya IBO (2016) Muscovy Duck Parvovirus Infection with Epicarditis in Bali, Indonesia. J Veterinar Sci Techno 7: 328. doi:10.4172/2157-7579.1000328

Page 5 of 5

Muscovy duck flocks in Fujian Province, China. The Journal of Veterinary Medical Science 75: 1127-1130.

18. Ji J, Xie QM, Chen CY, Bai SW, Zou LS, et al. (2010) Molecular detection of Muscovy duck parvovirus by loop-mediated isothermal amplification assay. Poultry Science 89: 477-483.

19. OIE (2014) Newcatle disease. In: Manual of Diagnostic Tests and Vaccines for Terrestrial Animals, OIE-Rome.

20. Creelan JL, Graham DA, McCullough SJ (2002) Detection and differentiation of pathogenicity of avian paramyxovirus serotype 1 from field cases using one-step reverse transcriptase-polymerase chain reaction. Avian Pathology 31: 493-499.

21. Mahardika GN, Jonas M, Murwijati T, Fitria N, Suartha IN, et al. (2016) Molecular analysis of hemagglutinin-1 fragment of avian influenza H5N1 viruses isolated from chicken farms in Indonesia from 2008 to 2010. Vet Microbiol 186: 52-58.

22. Tamura K, Peterson D, Peterson N, Stecher G, Nei M, et al. (2011) MEGA5: molecular evolutionary genetics analysis using maximum likelihood, evolutionary distance, and maximum parsimony methods. Molecular Biology and Evolution 28: 2731-2739.

23. Dai Y, Cheng X, Liu M, Shen X, Li J, et al. (2014) Experimental infection of duck origin virulent Newcastle disease virus strain in ducks. BMC Veterinary Research 10: 164.

24. Shi SH, Huang Y, Cui SJ, Cheng LF, Fu GH, et al. (2011) Genomic sequence of an avian paramyxovirus type 1 strain isolated from Muscovy duck (Cairina moschata) in China. Arch Virol 156: 405-412.

25. Mc LM, Priyono W, Bett B, Al-Qamar S, Claassen I, et al. (2014) Antibody response and risk factors for seropositivity in backyard poultry following mass vaccination against highly pathogenic avian influenza and Newcastle disease in Indonesia. Epidemiology and Infection pp: 1-11.

26. Forrester NL, Widen SG, Wood TG, Travassos da Rosa AP, Ksiazek TG, et al. (2013) Identification of a new Newcastle disease virus isolate from Indonesia represents an ancestral lineage of class II genotype XIII. Virus Genes 47: 168-172.

27. Xiao S, Paldurai A, Nayak B, Samuel A, Bharoto EE, et al. (2012) Complete genome sequences of Newcastle disease virus strains circulating in chicken populations of Indonesia. Journal of Virology 86: 5969-5970.
28. Adi AA, Astawa NM, Putra KS, Hayashi Y, Matsumoto Y (2010) Isolation and characterization of a pathogenic Newcastle disease virus from a natural case in indonesia. J Vet Med Sci 72: 313-319.

29. Yupiana Y, de Vlas SJ, Adnan NM, Richardus JH (2010) Risk factors of poultry outbreaks and human cases of $\mathrm{H} 5 \mathrm{~N} 1$ avian influenza virus infection in West Java Province, Indonesia. International Journal of Infectious Diseases 14:e800-805.

30. Robert M, Holle du RV, Setiawaty V, Pangesti KN, Sedyaningsih ER (2010) Seroprevalence of avian influenza A/H5N1 among poultry farmers in rural Indonesia, 2007. Southeast Asian J Trop Med Public Health 41: 1095-1103.

31. Roche SE, Cogger N, Garner MG, Putra AA, Toribio JA (2014) Assessing the risk of highly pathogenic avian influenza $\mathrm{H} 5 \mathrm{~N} 1$ transmission through poultry movements in Bali, Indonesia. Preventive Veterinary Medicine 113: 599-607.

32. OIE (2014) Duck Virus Hepatitis. In: OIE Terrestrial Manual. OIE-Rome, pp: 1-11.

33. Pugh JC, Simmons H (1994) Duck hepatitis B virus infection of Muscovy duck hepatocytes and nature of virus resistance in vivo. J Virol 68: 2487-2494.

34. Erdman DD, Durigon EL, Wang QY, Anderson LJ (1996) Genetic diversity of human parvovirus B19: sequence analysis of the VP1/VP2 gene from multiple isolates. J Gen Virol 77 : 2767-2774.

35. López-Bueno A, Villarreal LP, Almendral JM (2006) Parvovirus variation for disease: a difference with RNA viruses. Curr Top Microbiol Immunol 299: 349-370.

36. Zhu Y, Zhou Z, Huang Y, Yu R, Dong S, et al. (2014) Identification of a recombinant Muscovy Duck parvovirus (MDPV) in Shanghai, China. Vet Microbiol 174: 560-564.

37. Gough RE, Spackman D (1982) Studies with a duck embryo adapted goose parvovirus vaccine. Avian Pathol 11: 503-510.

38. Maurin-Bernaud L, Goutebroze S, Merdy O, Chanay A, Cozette V, et al. (2014) Efficacy of a new attenuated duck parvovirosis vaccine in Muscovy ducks. Vet Rec 175: 281.

39. Barnes HJ (1997) Muscovy Duck Parvovirus. In: Disease of Poultry (10th edn.) Calnek BW, Barnes HJ, Beard CW, McDonald LR, Saif YM (eds.) London: Iowa State University Press, Ames/Mosby-Wolfe, pp: 1032-1033. 